\title{
PENDAMPINGAN PEMBELAJARAN MATEMATIKA ASYIK DAN MENYENANGKAN MELALUI PENERAPAN SOFTWARE GEOGEBRA DAN MICROSOFT MATHEMATICS BAGI GURU MATEMATIKA SMA SE-FLORES
}

\author{
Natalia Rosalina Rawa1), Maria Editha Bela2), Melkior Wewe ${ }^{3)}$ \\ ${ }^{1,2,3)}$ Pendidikan Matematika \\ 1,2,3)Sekolah Tinggi Keguruan dan IImu Pendidikan Citra Bakti \\ ${ }^{1)}$ nataliarosalinarawa@gmail.com, ${ }^{2)}$ itabella09@gmail.com, ${ }^{3)}$ melkiorwewe1@gmail.com
}

\begin{abstract}
Histori artikel
Received:

15 Maret 2020

Accepted:

11 April 2020

Published:

15 April 2020

Abstrak

Pengabdian kepada masyarakat ini dilatar-belakangi oleh permasalahan yang dialami guru matematika SMA di Flores-NTT yaitu 1) kegiatan pembelajaran belum sepenuhnya memanfaatkan teknologi, dimana guru hanya mampu menggunakan media power point sehingga kegiatan pembelajaran terpusat pada guru, 2) tidak semua guru terlibat dalam pelatihan yang menekankan pada pengembangan keterampilan menggunakan software dalam pembelajaran matematika seperti GeoGebra, Microsoft Mathematic, Sematics, Cabri, Geometer's SketchPad dan lain-lain. Sehingga tujuan kegiatan ini adalah memberikan pendampingan pembelajaran matematika asyik dan menyenangkan melalui penerapan software matematika (Geogebra dan Microsoft Mathematics) bagi guru matematika SMA Se-Flores. Hasil kegiatan yang diperoleh dari pelatihan dan pendampingan pemanfaatan software Geogebra dan Microsoft Mathematics dalam pembelajaran matematika adalah : (1) peserta telah berhasil mengoperasikan software Geogebra dan Microsoft Mathematics, (2) Peserta dapat menggunakan software Geogebra dan Microsoft Mathematics dalam memecahkan masalah matematika, (3) Peserta dapat menggambar grafik 2 dimensi, 3 dimensi maupun grafik animasi, (4) Guru matematika SMA Sedaratan Flores telah berhasil menggunakan software Geogebra dan Microsoft Mathematics dalam pembelajaran matematika.
\end{abstract}

Kata-kata Kunci: pembelajaran matematika, geogebra dan microsoft mathematics 
Abstract. This community services is motivated by problems experienced by high school mathematics teachers in Flores-NTT, namely 1) learning activities have not fully utilized technology, where teachers are only able to use power point media so that learning activities are centered on the teacher, 2) not all teachers are involved in training that emphasizes the development of skills using software in mathematics learning such as GeoGebra, Microsoft Mathematic, Sematics, Cabri, Geometer's SketchPad and others. So the purpose of this activity is to provide fun and enjoyable math learning assistance through the application of mathematical software (Geogebra and Microsoft Mathematics) for high school mathematics teachers in Flores. The results of the activities obtained from training and mentoring the use of Geogebra and Microsoft Mathematics software in learning mathematics are: (1) participants have successfully operated Geogebra and Microsoft Mathematics software, (2) Participants can use Geogebra and Microsoft Mathematics software in solving mathematical problems, (3) Participants can draw 2-dimensional, 3-dimensional and animated graphics, (4) Mathematics teachers at Sedaratan Flores High School have successfully used Geogebra and Microsoft Mathematics software in mathematics learning.

Keywords: mathematics learning, geogebra and microsoft mathematics

\section{PENDAHULUAN}

Di era revolusi industri 4.0 seyogyanya pembelajaran matematika diarahkan pada pendekatan yang berpusat pada peserta didik dan tidak menekankan pembelajaran hafalan. Hal ini dimaksudkan agar situasi belajar mengajar matematika menjadi lebih bermakna dan otentik. Menurut Moila (2006), penekanan pembelajaran hafalan telah berubah pada penekanan sekarang akan pada pengembangan keterampilan berpikir tingkat tinggi dan pemecahan masalah dalam Matematika. Penekanan ini mengharuskan guru berperan sebagai fasilitator dalam pembelajaran matematika. Guru juga dituntut memiliki pengetahuan matematika yang luas dan mampu menerapkan strategi pembelajaran yang sesuai untuk memenuhi gaya belajar dari peserta didik yang berbeda-beda. Guru juga harus mampu mengintegrasikan teknologi sebagai media ke dalam konteks pembelajaran matematika untuk memfasilitasi kemampuan berpikir siswanya.

Integrasi teknologi sebagai media ke dalam pembelajaran matematika dapat menggunakan software dinamis seperti Microsoft Mathematic, Sematics, GeoGebra, Geometer's SketchPad, Cabri, dan lain-lain. Menurut Kerrigan (dalam Mistretta, 2005), manfaat penggunaan software dinamis meliputi 1) mengembangkan kemampuan berpikir tingkat tinggi siswa; 2) mengembangkan kemampuan berhitung dan kemampuan komunikasi siswa; 3) memperkenalkan siswa untuk pengumpulan dan analisis data; 4) memfasilitasi siswa dalam mempelajari aljabar dan geometri.

Pentingnya pengintegrasian teknologi ke dalam pembelajaran matematika harus didukung oleh kemampuan dan kreativitas guru dalam menggunakan teknologi. Menurut Shahneaz, dkk (2014), Implementasi teknologi harus diidentifikasi oleh guru pada tahap perencanaan, kesiapan siswa, tujuan pembelajaran, metode penyajian, strategi evaluasi, kegiatan tindak lanjut dan lain-lain. Implementasi teknologi yang salah oleh guru dapat mempengaruhi hasil yang diinginkan. Hasil penelitian Uche dkk (2016) menunjukkan bahwa tingkat kesadaran guru abad ke-21 tidak terlalu menggembirakan, guru tidak menggunakan teknologi dalam pembelajaran di kelas dan lingkungan abad ke-21 dan telah mempengaruhi 
bidang materi pengajaran, strategi pengajaran dan lainnya. Lebih lanjut, Oladosu (2012) menunjukkan bahwa guru memiliki sikap yang tepat terhadap TIK tetapi tidak memiliki metodologi integrasi dalam pembelajaran yang memadai.

Kondisi ini juga ditemukan pada guru-guru matematika di daratan pulau Flores Nusa Tenggara Timur. Dari hasil identifikasi awal ditemukan bahwa 1) kegiatan pembelajaran belum sepenuhnya memanfaatkan teknologi, dimana guru hanya mampu menggunakan media power point sehingga kegiatan pembelajaran terpusat pada guru, 2) tidak semua guru terlibat dalam pelatihan yang menekankan pada pengembangan keterampilan menggunakan software dalam pembelajaran matematika seperti GeoGebra, Microsoft Mathematic, Sematics, Cabri, Geometer's SketchPad dan lain-lain.

Dari analisis situasi tersebut, tim pengabdian kepada masyarakat merancang kegiatan pengabdian yang selaras dengan tuntutan pendidikan di era revolusi industri 4.0 dengan judul "Pendampingan Pembelajaran Matematika Asyik Dan Menyenangkan Melalui Penerapan Software Geogebra dan Microsoft Mathematics Bagi Guru Matematika SMA SeFlores". Diharapkan melalui kegiatan ini, guru-guru matematika sedaratan Flores dapat mengembangkan pembelajaran yang inovatif dengan memanfaatkan teknologi terutama terampil menggunakan software pembelajaran dinamis untuk mendukung proses pembelajaran matematika di kelas.

\section{METODE PELAKSANAAN}

Kegiatan pengabdian kepada masyarakat ini dilaksanakan di tiap sekolah selama 4 bulan yang akan dilangsungkan satu kali dalam seminggu. Pelaksanaan dilakukan dalam tiga tahap, yaitu :

\section{Persiapan}

Pada tahap persiapan dilakukan observasi terhadap proses pembelajaran matematika di SMA/MA/SMK sedaratan Flores. Observasi dilakukan untuk mengetahui masalah apa yang terdapat dalam proses belajar mengajar. Setelah diketahui masalahnya maka disusun suatu solusi untuk diterapkan dalam tahap pelaksanaan.

2. Pelaksanaan

Proses pelaksanaan terbagi menjadi 2, yaitu:

a) Sosialisasi

Tahap ini bertujuan untuk memberikan pengetahuan kepada guru-guru matematika tingkat SMA/MA/SMK bahwa terdapat teknologi yang dapat digunakan oleh guru untuk mengajarkan matematika. Teknologi tersebut berupa software geogebra dan Microsoft Mathematics yang mempunyai bahasa pemrograman yang sederhana. Penggunaan software geogebra dan Microsoft Mathematics ini akan memudahkan guru dalam mengajarkan matematika khususnya pada jenjang SMA. 


\section{b) Pelatihan}

Pelatihan pemanfaatan software geogebra dan Microsoft Mathematics dalam pembelajaran matematika akan dilakukan secara praktik langsung. Masing-masing peserta akan memegang satu komputer/laptop dan langsung mempraktekkan apa yang dijelaskan oleh instruktur. Instruktur akan disediakan untuk membantu belajar para peserta

Pelatihan pemanfaatan geogebra dan Microsoft Mathematics secara garis besar terdiri dari 3 topik utama, yaitu :

1) Pengenalan dasar mengenai geogebra

- Menjalankan Program geogebra

- Penulisan Perintah Dasar

- Aturan Dasar Operasi Matematika Dalam geogebra

2) Penggunaan geogebra dalam menyelesaikan masalah matematika Geogebra merupakan salah satu software matematika dinamis yang memuat kajian geometri, aljabar, dan kalkulus. Geogebra dapat digunakan sebagai alat bantu belajar dan mengajar matematika, sebagai alat presentasi, serta sebagai alat memvisualisasi bentuk geometri dan lain-lain. Pada pembelajaran geometri bidang dapat digunakan sebagai media yang dapat menyampaikan konsep yang bersidat abstrak menjadi lebih konkrit.

3) Pengenalan dasar mengenai Microsoft Mathematics

- Menjalankan Program Microsoft Mathematics

- Penulisan Perintah Dasar

- Aturan Dasar Operasi Matematika Dalam Microsoft Mathematics

4) Penggunaan Microsoft Mathematics dalam menyelesaikan masalah matematika Microsoft Mathematics dapat membantu dalam memecahkan berbagai persamaan langkah demi langkah, memahami konsep dasar aljabar, trigonometri, fisika, kimia dan juga kalkulus. Microsoft Mathematics adalah perangkat lunak sejenis kalkulator namun memiliki fitur yang lebih legkap dan memiliki kemampuan menjabarkan secara detail langkah demi langkah penyelesaian suatu persoalan dalam disiplin imu pasti, tidak hanya matematika namun untuk ilmu fisika dan kimia. Namun penjabaran yang sangat detail hanya ditemui pada persoalan matematika

\section{Pendampingan}

Kegiatan pendampingan akan dilaksanakan setiap minggu untuk memastikan bahwa guruguru telah mengerti dan terampil dalam mengoperasikan software geogebra dan Microsoft Mathematics. Guru-guru mampu menguasai apa yang telah diajarkan selama pelatihan dan mampu menggunakan geogebra dan Microsoft Mathematics dalam kegiatan pembelajaran di kelas. 
Metode yang digunakan dalam kegiatan ini adalah metode ceramah, diskusi, demonstransi dan unjuk kerja. Tahap pertama, metode ceramah digunakan untuk menjelaskan dan memberi pemahaman tentang software matematika yang wajib dikuasai guru pada abad ke 21. Tahap kedua yakni diskusi di mana peserta diberi kesempatan untuk berdiskusi diikuti dengan tanya jawab jika ada hal-hal yang masih diragukan dan belum dipahami. Ketiga metode demonstrasi, yaitu di hadapan para peserta dijelaskan penggunaan software geogebra dan Microsoft Mathematics. Tahap keempat, peserta diminta atau ditugaskan untuk mendemonstrasikan penggunaan software geogebra dan Microsoft Mathematics. Selama peserta mempraktekkan pengggunaan software geogebra dan Microsoft Mathematics, tim pelaksana melakukan monitoring.

\section{HASIL DAN PEMBAHASAN}

\section{Hasil}

Pada tanggal 18 Agustus 2019 tim pengabdian kepada masyarakat mendatangi seluruh SMA/SMK/MA sedaratan Flores-NTT untuk memberikan undangan sekaligus bertemu langsung dengan guru matematika dan kepala sekolah. Hal ini dimaksudkan untuk memberikan penjelasan singkat mengenai Software Geogebra dan Microsoft Mathematics dan manfaatnya dalam pembelajaran matematika. Peneliti merasa perlu memberikan penjelasan agar guru matematika dan kepala sekolah mengetahui apa itu Geogebra dan Microsoft Mathematics dan bagaimana perananya dalam pembelajaran matematika.

Dua hari kemudian, yaitu tanggal 20 Agustus 2019 peneliti menelpon semua SMA/SMK/MA sedaratan Flores-NTT untuk konfirmasi kehadiran. SMAS Seminari Pius XII Kisol mengirimkan 3 guru, MAS Muhammadiyah Riung akan mengirimkan 2 guru, SMAK St. Fransiskus Xaverius Boawae 2 guru, SMA Negeri 1 Soa 2 guru, SMA Negeri 1 Mauponggo 2 guru, SMA Negeri 1 Aiemere 2 guru, SMAS Katolik Thomas Aquino Mataloko 2 guru, SMA Negeri 1 Inerie 2 guru, SMA Negeri 1 Golewa Selatan 2 guru, SMAS St. Clemens Boawae 2 guru, dan SMA Negeri 1 Boawae 2 guru .

Ada dua sekolah yang tidak mengirimkan guru matematika untuk mengikuti pelatihan, yaitu SMA Negeri 1 Bajawa dan SMAS Regina Pacis Bajawa. Jumlah peserta yang akan mengikuti pelatihan adalah 22 orang.

Pelatihan pemanfaatan Software Geogebra dalam pembelajaran matematika dilaksanakan pada tanggal 30 Agustus 2019. Pada sesi pertama topik yang diajarkan adalah pengenalan dasar mengenai Geogebra. Materi-materinya yaitu cara membuka Geogebra, menyimpan file, membuka file, tampilan Geogebra (worksheet, window). Tim pengabdian mengenalkan operasi sederhana pada Geogebra. Kemudian memberikan contoh bagaimana penggunaan gambar geometri tersebut pada Geogebra. 
Pada sesi pertama ini tim pengabdian juga menjelaskan perintah-perintah yang yang mungkin akan sering digunakan dalam mengoperasikan Geogebra. Untuk sesi yang kedua, peneliti menjelaskan tentang materi-materi matematika menggunakan Geogebra dan juga menyesuaikan dengan materi yang akan diajarkan oleh peserta di sekolah. Materi yang diajarkan adalah geometri, aljabar, dan kalkulus.

Pelatihan pemanfaatan Software Microsoft Mathematics dalam pembelajaran matematika dilaksanakan pada tanggal 30 Oktober 2019. Pada sesi pertama topik yang diajarkan adalah pengenalan dasar mengenai Microsoft Mathematics. Materi-materinya yaitu cara membuka Microsoft Mathematics, menyimpan file, membuka file, tampilan Microsoft Mathematics (worksheet, window). Tim pengabdian mengenalkan operasi sederhana pada Geogebra. Kemudian memberikan contoh bagaimana penggunaan operasi perhitungan tersebut pada Microsoft Mathematics.

Pada sesi berikut tim pengabdian menjelaskan perintah-perintah yang yang mungkin akan sering digunakan dalam mengoperasikan Microsoft Mathematics. Untuk sesi yang kedua, peneliti menjelaskan tentang materi-materi matematika menggunakan Microsoft Mathematics dan juga menyesuaikan dengan materi yang akan diajarkan oleh peserta di sekolah. Materi yang diajarkan adalah memahami konsep dasar aljabar, trigonometri, fisika, kimia dan juga kalkulus.

Pada tanggal 16 Nopember 2019, setiap guru dari masing-masing sekolah diundang untuk menghadiri "Workshop Pembelajaran Matematika Asyik Dan Meyenangkan Melalui Penerapan Software Matematika (Geogebra Dan Microsoft Mathematics)". Dalam kegiatan tersebut para guru didampingi tim pengabdian untuk melakukan diskusi dan tanya jawab terkait keterlaksanan penerapan software tersebut di sekolah masing-masing.

Peserta sangat tertarik dengan kedua software ini. Walaupun hanya animasi sederhana tetapi dapat membuat grafik menjadi lebih jelas karena dapat diputar dari berbagai sudut dan dapat digerakkan. Peserta antusias untuk membuat grafik animasi yang lain. Peserta menyatakan bahwa siswa akan tertarik jika grafik bisa dibuat animasi seperti ini. Peserta merasa sangat bermanfaat mengikuti pelatihan penggunaan Software Geogebra dan Microsoft Mathematics.

\section{Pembahasan}

Pengabdian kepada masyarakat yang dilaksanakan secara terjadwal merupakan salah satu kewajiban dosen STKIP Citra Bakti dalam melaksanakan tugas tridharma dengan dana bersumber dari DIPA STKIP Citra Bakti melalui unit pelaksana Pusat Penelitian dan Pengabdian kepada Masyarakat. Pelatihan dan pendampingan penggunaan Software Geogebra dan Microsoft Mathematics merupakan wujud nyata pengabdian kepada masyarakat dosen program studi pendidikan matematika STKIP Citra Bakti. Kegiatan 
pengabdian yang dilaksanakan kepada guru-guru matematika SMA dari tiga kabupaten yakni Manggarai Tinur, Ngada dan Nagekeo telah berlangsung dengan baik. Hal ini dapat dilihat dari apresiasi guru untuk mengikuti kegiatan pelatihan sangat tinggi. Hal ini mengindikasikan bahwa para guru menyambut positif kegiatan yang telah dilakukan. Sesuai dengan harapan para sekolah, mereka sangat mengharapkan adanya kegitan-kegiatan yang sifatnya memberi penyegaran bagi para guru di daerah ini, baik terkait dengan pendalaman materi bidang studi ataupun terkait dengan metode mengajar dan media pembelajaran.

Beberapa faktor yang mendukung terlaksananya pelatihan dan pendampingan penggunaan Software Geogebra dan Microsoft Mathematics ini antara lain: (1) terbukanya pihak sekolah dalam menerima kegiatan pengabdian kepada masyarakat yang ditawarkan oleh tim pengabdi; (2) adanya motivasi dan keinginan dari berbagai pihak, baik guru maupun siswa untuk mengikuti pelatihan ini; (3) adanya motivasi untuk mengembangkan hasil pelatihan ini ke dalam proses pembelajaran matematika yang mereka jalani. Hal ini didukung pula dari hasil analisis kuesioner yang dilakukan kepada peserta kegiatan yang menyatakan sebanyak $90,05 \%$ peserta kegiatan menyatakan sangat puas dengan kegiatan ini. Selain itu, sebanyak $80,25 \%$ peserta kegiatan menyatakan bahwa kegiatan ini menambah wawasan bagi mereka dalam hal software-software yang dapat membantu memecahkan permasalahan matematika.

Pelaksanaan kegiatan ini terdapat juga beberapa faktor penghambat, yaitu: (1) jaringan listrik yang kurang memadai disekitar lokasi mengakibatkan mobilitas tim pengabdian kepada masyarakat sedikit mengalami kendala; (2) terbatasnya jumlah komputer/laptop yang tersedia di sekolah tempat pelaksanaan pelatihan, sehingga ada beberapa peserta yang harus berbagi komputer/laptop selama pelatihan berlangsung.

Namun demikian Kepala sekolah dan guru-guru memberikan apresiasi terkait pelaksanaan kegiatan ini dan berharap pelaksanaan kegiatan dapat dilakukan secara berkesinambungan untuk membantu meningkatkan kompetensi pedagogik guru di sekolah. Kepala Sekolah juga menyarankan perlu ada kegiatan serupa yang dapat membantu guruguru untuk selalu siap menghadapi perkembangan era revolusi industri 4.0. Dalam kegiatan pendampingan dan pelatihan, guru-guru sangat antusias dalam menggunakan software Geogebra dan Microsoft Mathematics yang telah disiapkan oleh tim pengabdian kepada masyarakat. Secara umum kegiatan pengabdian berupa pelatihan dan pendampingan penggunaan Software Geogebra dan Microsoft Mathematics telah terlaksana dengan baik.

\section{KESIMPULAN}

Dari kegiatan pelatihan dan pendampingan yang telah dilakukan dapat diambil kesimpulan bahwa guru matematika merasakan manfaat yang nyata dari penggunaan Software Geogebra dan Microsoft Mathematics. Guru matematika merasakan perubahan 
respon siswa terhadap pelajaran matematika. Dari yang awalnya kurang tertarik menjadi antusias memperhatikan penjelasan guru. Guru ingin belajar lebih dalam lagi tentang Software Geogebra dan Microsoft Mathematics agar mempunyai ilmu menggunakan Software Geogebra dan Microsoft Mathematics dalam memecahkan berbagai masalah matematika.

Guru merasa terbantu dengan adanya software ini. Software ini dapat dimanfaatkan untuk semua materi matematika tetapi tidak semua materi matematika harus menggunakan Software Geogebra dan Microsoft Mathematics. Perlu selalu ada variasi metode dan media dalam mengajarkan matematika.

\section{DAFTAR PUSTAKA}

Moila, M.M. (2006). The use of educational technology in mathematics teaching and learning: an investigation of a south african rural secondary school. Minidissertation M.Ed. (CIE), Faculty of Education, University of Pretoria.

Mistretta, R.M. (2005). Integrating technology into the mathematics classroom: the role of the teacher preparation programs. The Mathematics Educator, 15(1), 18-24.

Shahneaz, M. A., Akhter, S., dan Yasmin, N. (2014). The impact of teacher and technology in class room. Journal of Education and Practice. 5(27), 79-82.

Oladosu, K. (2012). Basic technology teachers' awareness and attitude towards the use of information and communication technology for sustainable development in lagos state education districts: I, IV and VI. Journal of Education and Practice. 3(13), 4650.

Uche, C., Kaegon, Leesi, E. S. P., Okata, \& Fanny, C. (2016). Teachers' level of awareness of 21 st century occupational roles in rivers state secondary schools. Journal of Education and Training Studies. 4(8), 83-92. 